\title{
Opportunity costs of gastrointestinal endoscopic training in Canada
}

\author{
WT Depew BSc MD FRCPC, LC Hookey MD FRCPC, SJ Vanner MSc MD FRCPC, \\ JA Louw MBChB FRC(SA) MMed, CE Lowe MD FRCPC, MJ Ropeleski MD FRCPC, \\ MJ Beyak BSc MD FRCPC, A Lazarescu MD FRCPC, WG Paterson BSc MD FRCPC
}

WT Depew, LC Hookey, SJ Vanner, et al. Opportunity costs of gastrointestinal endoscopic training in Canada. Can J Gastroenterol 2010;24(12):733-738.

BACKGROUND: No data exist to define the opportunity costs related to instruction in endoscopic procedures in Royal College of Physicians and Surgeons of Canada-accredited teaching centres. Academic and institutional administrators expect staff to achieve acceptable performance standards. There is a need to measure some of the effects of training activity in the establishment of such standards. OBJECTIVE: To measure the effect of resident training in colonoscopy on real procedure times and, as a secondary goal, to estimate procedural losses related to the process of training.

METHODS: Real procedure times for ambulatory colonoscopy in a single academic, hospital-based endoscopy unit were documented. Times for certified endoscopy instructors functioning solo were compared with times for procedures involving trainees at several levels of colonoscopic experience. Procedural reductions associated with resident training were estimated based on the parameters derived from the results. The analysis was executed retrospectively using prospectively collected data.

RESULTS: Resident training prolonged procedure times for ambulatory colonoscopy by $50 \%$. The trainee effect was consistent, although variable in degree, among a variety of endoscopy instructors. Such increased procedure times have the potential to reduce case throughput and endoscopist remuneration.

CONCLUSIONS: Resident training in colonoscopy in a Canadian certified training program has significant negative effects on case throughput and endoscopist billings. These factors should be considered in any assessment of performance in similar training environments.

Key Words: Endoscopy; Opportunity cost; Resident training

astrointestinal endoscopy is an integral component of J investigation and treatment. The demand for endoscopic services has escalated as a consequence of not only the establishment of newly developed endoscopic techniques and interventions, but also the emergence of new indications and health care policies - in particular, the marked increase in the demand for screening colonoscopy for polyp/cancer detection. To satisfy such demands, endoscopic services provided in hospital-based units or independent facilities must be delivered safely, effectively and efficiently. Accordingly, all endoscopic practitioners must be adequately trained in appropriate clinical settings that address both the cognitive and technical aspects of endoscopic care.

\section{Les coûts de renonciation de la formation en endoscopie intestinale au Canada}

HISTORIQUE : Il n'existe pas de données pour définir les coûts de renonciation liés à la formation sur les interventions endoscopiques dans les centres de formation agréés du Collège royal des médecins et chirurgiens du Canada. Les administrateurs des universités et des établissements s'attendent que leur personnel atteigne des normes de rendement acceptables. Il est nécessaire de mesurer quelques-uns des effets de l'activité de formation dans la mise en œuvre de telles normes.

OBJECTIF : Mesurer l'effet de la formation des résidents en coloscopie sur la durée d'intervention réelle et, dans un deuxième temps, évaluer les pertes liées aux interventions effectuées dans le processus de formation.

MÉTHODOLOGIE : Les chercheurs ont documenté la durée réelle des coloscopies ambulatoires dans l'unité d'endoscopie d'un seul hôpital universitaire. Ils ont comparé la durée requise pour des formateurs agréés en endoscopie travaillant seuls à la durée d'intervention des apprenants à diverses étapes de leur expérience de coloscopie. Ils ont évalué la diminution du nombre d'interventions associée à la formation des résidents d'après des paramètres dérivés des résultats. Ils ont procédé à une analyse rétrospective au moyen de données colligées prospectivement.

RÉSULTATS : La formation des résidents prolongeait la durée des coloscopies ambulatoires de $50 \%$. L'effet de la présence de l'apprenant était constant, quoique variable, chez divers formateurs en endoscopie. Une telle augmentation de la durée d'intervention risque de réduire le débit des cas et la rémunération des endoscopistes.

CONCLUSIONS: La formation des résidents en coloscopie dans un programme de formation agréé canadien nuit considérablement au débit et à la facturation des endoscopistes. Il faut tenir compte de ces facteurs dans une évaluation du rendement de milieux de formation similaires.

Notwithstanding the initial transient effects of simulator training devices on early (fewer than 50 cases) endoscopic competence, most endoscopy instructors would concede that procedures involving resident learners take longer than those performed by certified specialists working alone. Although many training groups have examined criterion-based competency learning curves, there are few data describing the quantitative effects of training on endoscopy procedure times. McCashland et al (1) examined the implications of endoscopic training on both facility time use and endoscopist earnings. Using the Clinical Outcomes Research Initiative database to compare many private practices, academic medical centres and Veterans Administration hospitals, they determined average

Gastrointestinal Diseases Research Unit, Queen's University School of Medicine, Hotel Dieu Hospital, Kingston, Ontario

Correspondence: Dr William T Depew, Hotel Dieu Hospital - Queen's University, 166 Brock Street, Kingston, Ontario K7L 5G2.

Telephone 613-544-3310 ext 249, fax 613-544-3114, e-mail depeww@hdh.kari.net

Received for publication February 1, 2010. Accepted June 29, 2010 
TABLE 1

Trainee participation increases procedure times across a broad array of surgical interventions

\begin{tabular}{lcl}
\hline Procedure & $\Delta \mathbf{T}, \%$ & Author (reference) \\
\hline Laparoscopic cholecystectomy & 11 & Bridges (4) \\
24 & Koperna (5) \\
37 & Babineau et al (6) \\
& 49 & Traverso et al (7) \\
Hernia repair & 16 & Bridges and Diamond (4) \\
& 21 & Babineau et al (6) \\
Bowel resection & 71 & Koperna (5) \\
Appendectomy & 26 & Babineau et al (6) \\
Carotid endarterectomy & 86 & Bridges and Diamond (4) \\
Hip arthroplasty & 37 & Bridges and Diamond (4) \\
Knee arthroplasty & 35 & Babineau et al (6) \\
Video-assisted thoracoscopic surgery & 20 & Woolson and Kang (8) \\
Anterior repair & 18 & Woolson and Kang (8) \\
Combined repair & 18 & Auerbach et al (9) \\
Arthroscopic ACL repair & 8 & Auerbach et al (9) \\
\hline
\end{tabular}

The increase in mean time $(\Delta T)$ is represented as a percentage of the procedure time logged by instructors working alone. ACL Anterior cruciate ligament

per-case real procedure time increases of $2 \mathrm{~min}$ to $5 \mathrm{~min}$ for upper endoscopy, and $3 \mathrm{~min}$ to $16 \mathrm{~min}$ for colonoscopy. Overall, procedure times increased from $10 \%$ to $37 \%$ when trainees were involved. In a model including 4000 cases per year (2000 upper endoscopies and 2000 colonoscopies), the estimated financial disadvantage for endoscopy instructor-based activity, based on 1999 Medicare reimbursement information, ranged from US\$500,000 to US\$1,000,000.

Additional evidence supporting the notion that resident training in technical performance prolongs procedure times is documented in the surgical literature. As shown in Table 1, procedure time prolongation has been quantified across a broad array of surgical interventions. Notwithstanding the substantial variation in the magnitude of the training effects, even for identical procedures, related primarily to differences in study definitions of procedure times and sites, there is remarkable consistency in the recognition of trainee-associated prolongation among many different procedures.

This is not a trivial matter. Institutional administrators are justifiably concerned about the efficient use of endoscopy resources. Most engaged endoscopy instructors find it difficult to teach effectively and meet 'independent peer' benchmarks for specialist endoscopy performance. Moreover, most endoscopy instructors cannot throughput as many cases per interval of teaching as solo certified practitioners and, therefore, many must accept some measure of compromise in fee-for-service income arrangements. The creation of a potential conflict of interest is a concern. Practical matters including the construction of booking templates and the need for unit-staff overtime are also germane to the effects of endoscopy training programs on performance. Confirmation of the magnitudes of the effects of training times on endoscopy performance is clearly required if the influence of training on efficiency and throughput is to be properly assessed and compensated.
The primary aim of the present study was to quantify the effects of endoscopy training on actual procedure times for colonoscopy in a single Canadian ambulatory academic endoscopy training centre. A single ambulatory site was selected to reduce the influence of complicated therapeutic interventional endoscopy; minimize effects on timing attributable to different infrastructures, nursing practices and unit policies; and to enable direct comparisons among the same endoscopists performing the same procedures with and without trainees.

\section{METHODS}

The present study was conducted at an academic, hospital-based ambulatory endoscopy facility. The facility has been in operation as an ambulatory-restricted unit for more than 14 years. The three-room unit operates with a dedicated endoscopy nursing staff, the composition of which was unchanged during data collection. The endoscopy rooms are supported by a dedicated 10-bed preparation and recovery area, staffed by nurses with no responsibilities to the procedure rooms and onsite endoscope reprocessing capability with dedicated endoscope technicians. The unit operates with clearly established policies, a fixed universal scheduling template and a stable infrastructure. The data collection interval extended from July 1, 2002 to June 30, 2007.

As a consequence of the unit's operational quality assurance program, procedural data were routinely collected prospectively pro forma for all patients attending the unit during the study interval. These data, captured by the responsible endoscopy nurse included, among other items, records of the start and stop times of each procedure to the nearest minute, the identity of the staff endoscopist and the identity of any trainee who may have participated. All data were available in annual reports that were stored in an electronic database. The analysis was conducted retrospectively.

The recorded start times were the clock times of the initiation of the administration of intravenous sedation. In the minority of cases in which sedation was not used, the start time was the clock time at the point of colonoscope insertion. The recorded stop times were the clock times at which the instrument was fully withdrawn. In an effort to isolate technical procedure times, time spent with preprocedural patient evaluation and chart review, and postprocedural record keeping were not included. The procedure time (in min) was calculated as a simple subtraction (ie, stop - start).

No attempt was made to stratify cases for mucosal biopsy, polypectomies, cecal/ileal intubation rates or premature termination rates. Patients undergoing both upper endoscopy and colonoscopy on the same day were excluded from analysis. Such cases represented less than $10 \%$ of the total case load. In this particular academic unit, all cases are considered to be eligible teaching cases. Trainees attended in routine rotations in all sessions. In less than $1 \%$ of the cases, staff endoscopists explicitly excluded trainees. The majority of these biased-case selections represented difficult cases (eg, previous incomplete, technically complex colonoscopy or large sessile polypectomy) or unique patient-related requests. Only adult patients were included.

The trainees included all residents in the Royal College of Physicians and Surgeons of Canada Gastroenterology Training Program at Queen's University Medical School (Kingston, Ontario) and the majority of residents in the general surgery 
program. First- and second-year gastroenterology residents (postgraduate year [PGY] 4 GI and PGY5 GI) complete two years of graded endoscopic instruction. General surgery residents, usually at the PGY3 or PGY4 level, usually completed only four to six months of training.

The experienced endoscopists included eight gastroenterologists and four general surgeons. The majority of instruction was delivered by the gastroenterologists. Individual endoscopists were allowed to instruct according to their own styles. There were no uniform criteria used to define the specific roles of the endoscopists in procedural activities initiated by trainees. In most instances, the supervising endoscopist attended only one procedure at a time. Other endoscopists $(n=5)$ performing fewer than 100 procedures per year were excluded.

To estimate the effects of endoscopy instruction on actual caseloads and endoscopist remuneration, two different strategies were used. First, a procedure rate was calculated using the average measured real procedure time increased by $10 \mathrm{~min}$ to allow for initial patient preparation (physician introduction and intravenous placement) and case completion activities (documentation/dictation). A nonprocedural time of $10 \mathrm{~min}$ per case reflected the fact that fewer than $2 \%$ of the cases required any onsite antecedent history or physical examination, and the majority of the cases were reviewed by the referring consultant remote from the endoscopy room following procedure completion. Moreover, patient preparation and recovery was executed remote from the endoscopy room by independent - but dedicated - nursing personnel, resulting in minimal additional time for room turnover. Second, a procedure model was constructed for a single endoscopist in a oneroom unit with $480 \mathrm{~min}$ of procedure time available per session. This simple model enabled some theoretical comparisons between trainee-associated and solo-expert colonoscopy throughputs under different teaching commitment conditions.

The primary analysis was a comparison of colonoscopy procedure times for endoscopy instructors functioning with and without trainee participation. Secondary analyses compared times between gastroenterology and general surgery trainees, times between gastroenterologists and general surgeons, and times between PGY4GI and PGY5GI trainees. To compare procedure times according to the density of trainee participation per instructor, mean times were correlated with a calculated trainee fractional rate (TFR). For each instructor, the TFR was calculated with the following formula:

\section{TFR $=$ Caseload with trainees/total caseload for each procedure type}

Comparisons between and among the groups were undertaken using Student's $t$ test and ANOVA as indicated. Post hoc testing was executed using Dunnett's T3 test. Pearson correlations were determined as indicated. For each set of calculations, the results are presented as the mean with 95\% CI. All statistical analyses were performed using SPSS version 17.0 (SPSS Inc, USA).

\section{RESULTS}

A total of 17,948 single scheduled ambulatory procedures (upper endoscopy, colonoscopy or sigmoidoscopy) were completed during the study interval. Of these, 7935 colonoscopies were eligible for the present analysis. Eight gastroenterologists

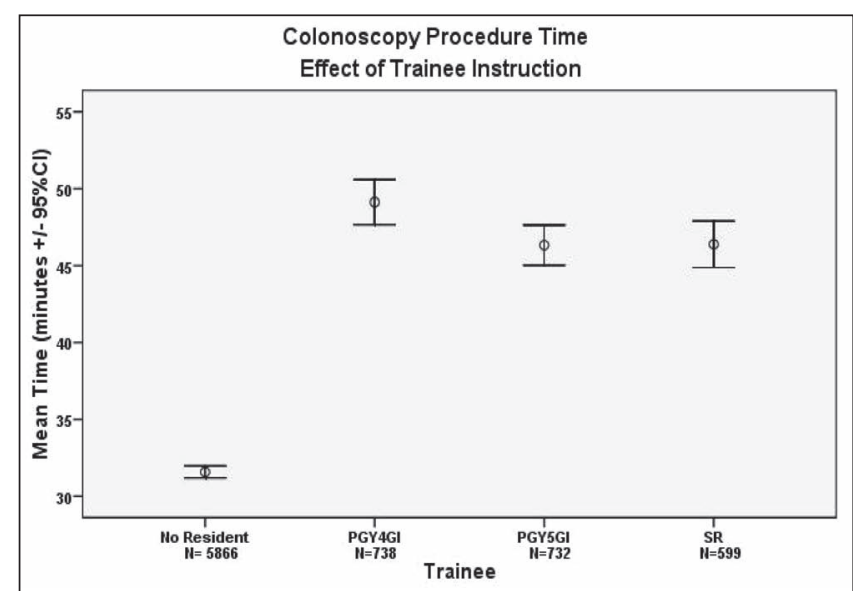

Figure 1) Colonoscopy procedure time. Effect of trainee instruction. Colonoscopy procedure times were significantly longer when trainees were involved. The effect was evident across all trainee levels. $(P<0.001$ [ANOVA]; P<0.001 [Dunnett's T3]). PGY4GI Firstyear gastroenterology residents; PGY5GI Second-year gastroenterology residents; SR General surgery residents

performed between 183 and 1060 procedures (median 636 procedures), while four general surgeons performed between 294 and 986 procedures (median 785 procedures). Of the 31 trainees included, 10 gastroenterology residents performed between nine and 247 colonoscopies (median 213 procedures), and 21 general surgical residents performed between two and 92 colonoscopies (median 25 procedures). The lowest numbers of procedures were recorded by trainees whose exposures overlapped either the beginning or the end of the data collection interval.

Mean ( \pm SD) colonoscopy procedure times for experienced endoscopists (5866 cases, $31.6 \pm 15.3 \mathrm{~min}$ ) were significantly shorter than times for PGY4GI trainees (738 cases, 49.1 $\pm 20.2 \mathrm{~min}$ ), PGY5GI trainees (732 cases, $46.3 \pm 18 \mathrm{~min}$ ) and surgical trainees (599 cases, $46.4 \pm 18.8 \mathrm{~min}) \quad(\mathrm{P}<0.001$ [ANOVA]; $\mathrm{P}<0.001$ [Dunnett's T3]). There was a small difference (mean $-2.7 \mathrm{~min}$ ) between PGY4GI and surgical trainees $(\mathrm{P}=0.03$ [Dunnett's T3]) (Figure 1). The aggregate effects of training on colonoscopy were substantial. Procedure times increased from $31.6 \pm 15.3 \mathrm{~min}$ to $47.3 \pm 19.1 \mathrm{~min}(\mathrm{P}<0.001)$ - an average increase of $15.7 \mathrm{~min}(49.7 \%$ ) (Figure 2). Similar results were observed with upper endoscopy, in which the overall mean increase in procedure time was $7.6 \mathrm{~min}$ (data not shown).

General surgeons were responsible for 2850 colonoscopies, of which $271(9.5 \%)$ were trainee cases. One surgical colonoscopist used conscious sedation in less than $50 \%$ of his cases. Procedure times increased from $26.3 \pm 13.3 \mathrm{~min}$ to $38.6 \pm 15.5 \mathrm{~min}$ $(\mathrm{P}<0.001)$. Gastroenterologists attended 5085 procedures, of which 1798 (35\%) were trainee cases. Procedure times increased from $35.7 \pm 15.6 \mathrm{~min}$ to $48.6 \pm 19.2 \mathrm{~min}(\mathrm{P}<0.001)$. There were small but significant differences $(\mathrm{P}<0.001$ [ANOVA]; $\mathrm{P}<0.01$ [Dunnett's T3]) among the trainee groups compatible with the level of instruction (PGY4GI, 49.1 $20.2 \mathrm{~min}$; PGY5GI, $46.3 \pm 18 \mathrm{~min}$; surgical trainees, $52.5 \pm 18.9 \mathrm{~min}$ ).

There was considerable variation in individual procedure times for the endoscopists. For colonoscopy, the shortest average time was $23.1 \pm 11.3 \mathrm{~min}$; the longest was double this, at $48.3 \pm 22 \mathrm{~min}$. The colonoscopists with the longest times customarily performed 


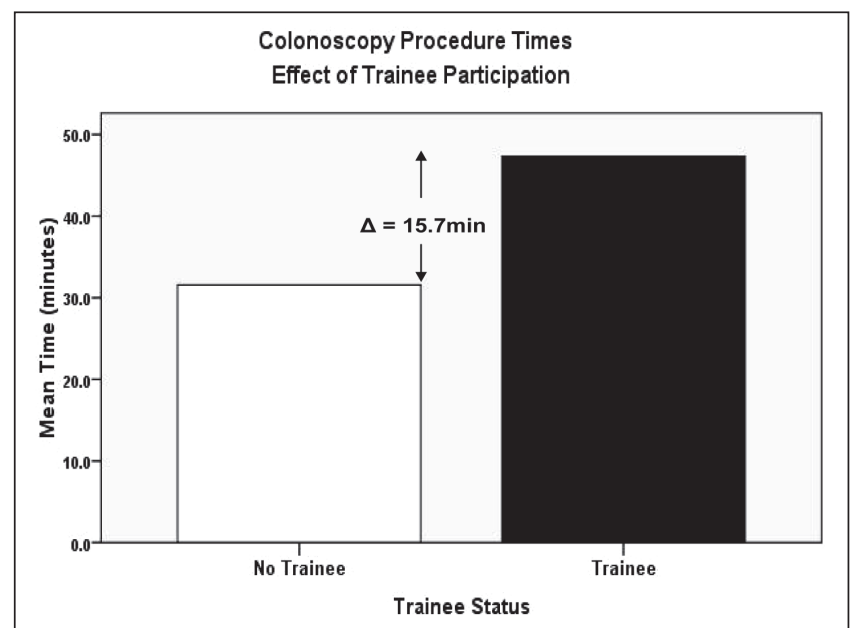

Figure 2) Colonoscopy procedure time. Effect of trainee participation. The increase in average colonoscopy procedure time with trainees was $15.7 \mathrm{~min}(49.7 \%)(P<0.001)$

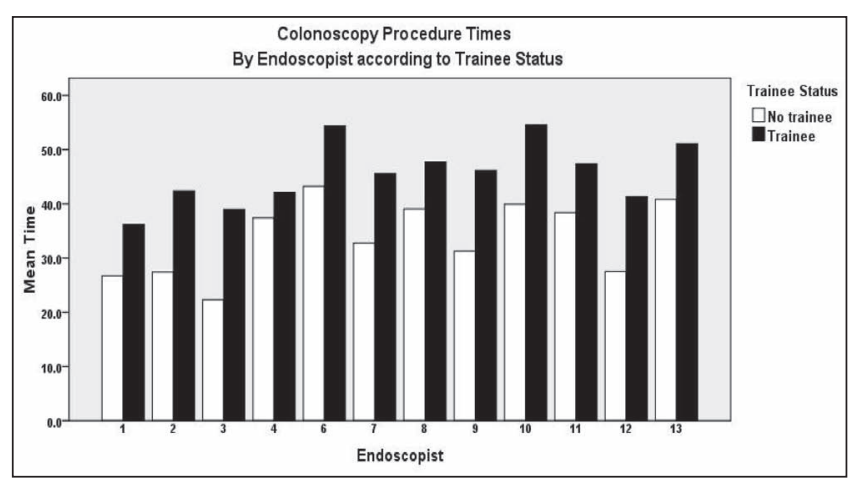

Figure 3) Colonoscopy procedure times stratified by endoscopist according to trainee status. Mean colonoscopy procedure times $(\mathrm{min})$ were increased significantly for each endoscopist with trainees $(P=0.002$ [Wilcoxon signed-rank test])

the most large/complex lesion polypectomies (often using endoscopic mucosal resection techniques). However, procedure times increased for all endoscopists when trainees participated (Figure 3). Accordingly, even individual differences in instructor skill levels, experience and teaching styles did not appear to vitiate the trainee effect on procedure time.

There was a clear, positive correlation between overall colonoscopy procedure times and the TFRs for all endoscopists (Pearson $\mathrm{r}=0.87, \mathrm{P}<0.001$ ) (Figure 4). There was no correlation between total caseloads per endoscopist and procedure times (Pearson $\mathrm{r}=-0.51, \mathrm{P}=0.09$ ). Likewise, there was no significant correlation evident between trainee colonoscopy procedure times and trainee caseloads among the endoscopists (Pearson $\mathrm{r}=0.56, \mathrm{P}=0.058$ ) (Figure 5). Accordingly, it appears that the complexity of the caseload and the number of cases undertaken with trainees exert dominant effects on individual endoscopy instructor procedure time variations.

The trainee effect was estimated using a procedure rate calculation. Assuming each procedure included a nonprocedural time commitment of $10 \mathrm{~min}$ for patient preparation and case completion, the colonoscopy rates were 1.05 cases/h and 1.43 cases/h with and without trainees, respectively, a difference of 0.38 cases/h. Using the Ontario Health Insurance Schedule of Benefits (April 1, 2008 version) this difference translated

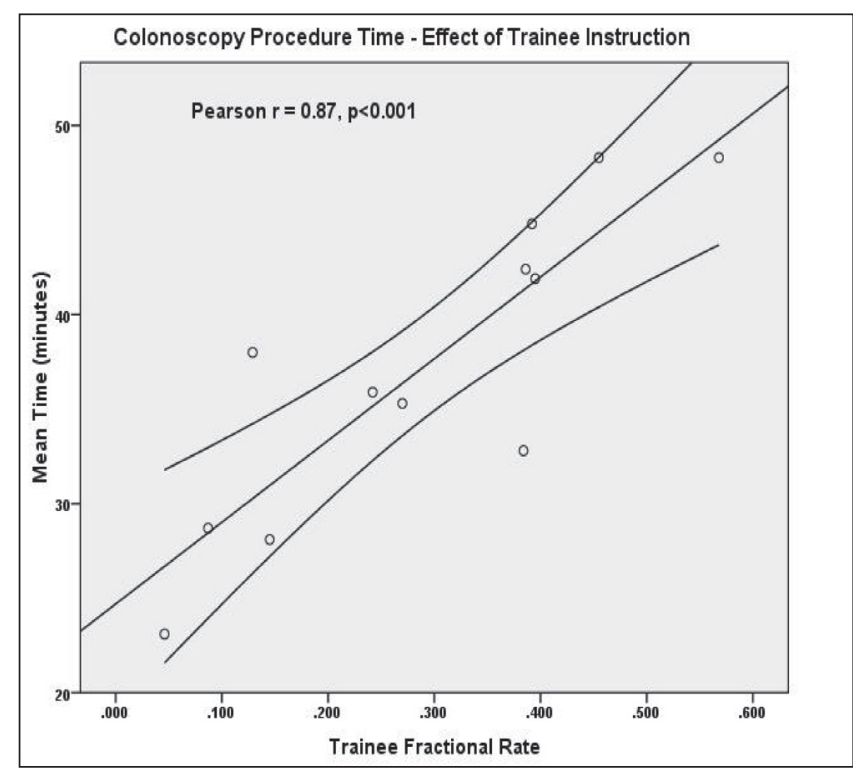

Figure 4) Colonoscopy procedure time. Effect of trainee instruction. Endoscopy instructor mean colonoscopy procedure times were strongly correlated with increasing instructional commitment. Trainee fractional rate $=$ cases with trainees/total cases (Pearson correlation with $95 \% \mathrm{CI}$ )

into a minimum hourly income loss due to training activities of $\$ 85.45$. These losses increase according to the frequencies of biopsy and polypectomy. Indeed, if colonoscopy with single polypectomy is routine in each case, the loss due solely to training, according to the rate model, is at least $\$ 144.00 / \mathrm{h}$ for each case.

A theoretical one-room model for colonoscopy, based on the parameters defined in the present study, is depicted in Table 2. The range of procedural mixes accommodated in $480 \mathrm{~min}$ of unit time (allowing up to $0.5 \mathrm{~h}$ overrun per session) for one endoscopist with or without a trainee illustrates, in a more practical manner, the reductions in caseloads to be expected. For the present study, such a model predicts a loss of one colonoscopy for each surgical session (9.5\% trainee participation) and two colonoscopies for each gastroenterology session (35\% trainee participation).

\section{DISCUSSION}

The current study demonstrated significant opportunity costs associated with endoscopic instruction, both for throughput and financial compensation. Average colonoscopy procedure times were extended by $50 \%$. Very similar observations were made by McCashland et al (1). Such increments likely represent minimum training effects. It is probable that trainees require more time than experienced endoscopists, both to assess cases preprocedurally and to record the event details postprocedure. Moreover, only stable ambulatory cases were included. The majority of these cases involved routine procedures without requirements for advanced endoscopic techniques. It is probable that extension of such analyses to more complex outpatients and inpatients with additional comorbidities would reveal even greater effects on trainee procedure times.

The effects of endoscopy instruction can also be seen in the relationship between individual endoscopist procedure times 


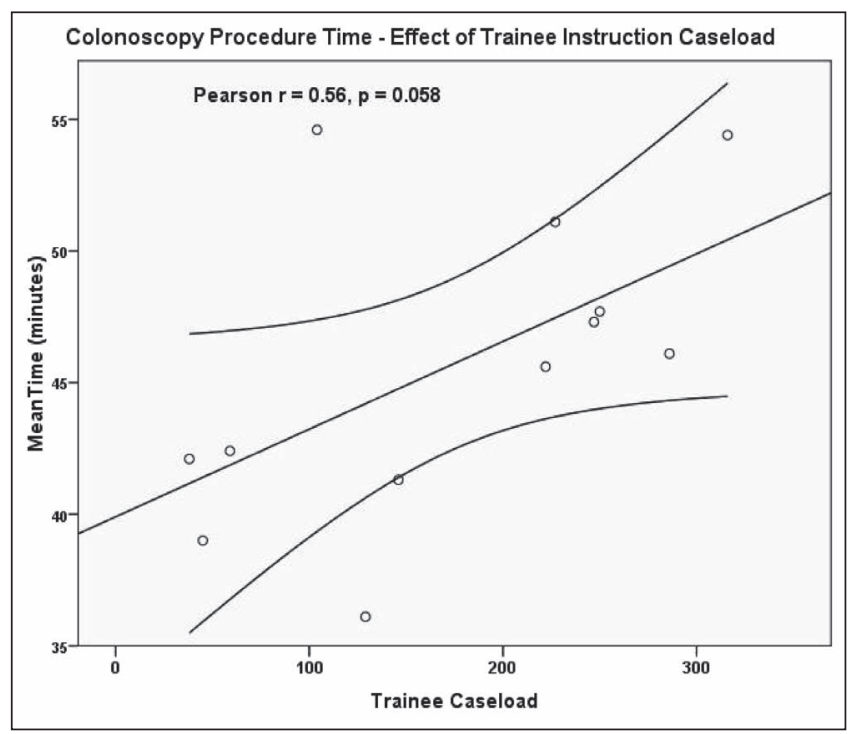

Figure 5) Colonoscopy procedure time. Effect of trainee instruction caseload. For trainee colonoscopies alone, endoscopy instructor mean procedure time was not significantly related to trainee caseload (Pearson correlation with 95\% CI)

and trainee involvement. Endoscopists with the largest teaching commitments - quantified by the TFR - had the longest mean procedure times.

The present study only measured actual procedural times as defined. Procedural mix and patient preparation and recovery algorithms will vary from unit to unit. There are many variables that influence general efficiency. These variables will be modified according to the nature of the unit structure, staffing and modus operandi. The training time variable was isolated deliberately to define a training effect in isolation in a single centre. The net effect of procedural prolongation on overall unit efficiency cannot be predicted with precision in the absence of such additional data. Likewise, the present study made no attempt to measure other important costs such as lost endoscopy nursing resources. For the theoretical model, such opportunity costs would parallel the reductions in caseloads.

The theoretical model was developed for a single-room unit. It assumes that the endoscopy instructor is present with the trainee throughout the procedure and that increased throughput cannot be achieved by the simultaneous use of more than one room. With more experienced trainees, it can be argued that the effect of teaching may be attenuated by parallel colonoscopies performed independently by the instructor.

Some have argued that procedure time constitutes a small and insignificant component of the overall time spent in endoscopy unit activities, and that modification in procedure time alone will not provide additional procedural space $(2,3)$. However, using the results of the current study in similarly organized units, it can be projected that, on average, for every two colonoscopies undertaken with trainees, the additional time expended is equivalent to one expert colonoscopy procedure. In a mixed model governed by the parameters established in the present study, the caseload deficit for an expert endoscopist may be up to four colonoscopies per $8 \mathrm{~h}$ session depending on the proportion of cases performed with trainees.
TABLE 2

Effect of trainee instruction on caseload. Theoretical caseloads determined for a single $480 \mathrm{~min}$ session allowing up to $\mathbf{3 0}$ min overtime per session

\begin{tabular}{cccccc}
\hline \multicolumn{2}{c}{ Cases, $\mathbf{n}$} & & \multicolumn{2}{c}{ Cases, $\mathbf{n}$} \\
\cline { 5 - 6 } Trainee & Instructor & Total fractional & & \\
(0.95 h/case $)$ & $(\mathbf{0 . 7 0}$ h/case $)$ & rate, $\%$ & Total & Deficit \\
\hline 0 & 12 & 0 & 12 & 0 \\
1 & 10 & $9^{*}$ & 11 & 1 \\
2 & 9 & 18 & 11 & 1 \\
3 & 7 & $30^{\star *}$ & 10 & 2 \\
4 & 6 & $40^{* *}$ & 10 & 2 \\
5 & 5 & 50 & 10 & 2 \\
6 & 2 & 75 & 8 & 4 \\
7 & 1 & 88 & 8 & 4 \\
8 & 0 & 100 & 8 & 4 \\
\hline
\end{tabular}

Solo instructor times are estimated from the study parameters at $0.70 \mathrm{~h} /$ case and trainee-associated times at $0.95 \mathrm{~h} /$ case. Depending on the proportion of cases undertaken with trainees, the caseload sacrificed during training ranges from one to four. For the trainee involvement characterizing the current study, general surgeons* lost one case per session and gastroenterologists ** lost two

The current study was not designed to identify the precise sources of the procedural prolongations. Different trainees require different types of instruction depending on innate skills and level of experience. Interestingly, although there was a significant decrease in procedure time prolongations between PGY4GI and PGY5GI trainees, the magnitude of the average reduction $(-2.8 \mathrm{~min})$ was small. This was likely related to the instructors' deliberate attempts to allow senior trainees to execute more of the procedural components independently. For the senior trainees, the gains in technical experience were attenuated by increased procedural responsibilities.

Different endoscopy instructors vary in their approaches to teaching. Procedural objectives and patient characteristics also influence procedure times. However, the trainee effects were consistent for an eclectic array of instructors (gastroenterologists and general surgeons). Accordingly, it is reasonable to accept that the very act of instruction results in procedural prolongation, which is independent of instructor style. In the present study, the relative prolongation in procedure time was similar for most instructors. The instructor with the shortest average solo procedure time experienced the longest absolute trainee prolongation time. There was no correlation between instructor solo times and trainee time prolongations (Pearson $\mathrm{r}=-0.52, \mathrm{P}=0.08)$. Although this observation does not eliminate some unidentified instructor biases in determining trainee prolongation, it does not support the existence of a systematic instructor-based dominant effect.

The trainee effect measured in the current study was substantial. This particular training facility used individual expert opinion to determine the length of time a trainee was allowed to continue uninterrupted in any given case. Alternative models that operate with established, standard, goal-oriented procedural limitations, based either on staged experience-defined (eg, number of cases) time limits or intestinal landmarks, might improve training efficiency and reduce the magnitude of the effect. However, such standardized methods might also compromise the training process by reducing the opportunities for trainees to grapple with the range of mechanical problems 
inherent in these procedures. The establishment and application of standard sets of staged procedural skills require careful planning and efficacy analyses before such methodology can confidently replace traditional expert-based tutelage. Until such standardized methods have been shown to enable attainment of procedural competencies during the training interval, it seems premature to suggest that these apparent time-saving interventions should be introduced generally as practical solutions.

Intuitively, it makes sense that it takes longer, per case, to teach residents endoscopic skills. Trainees gravitate to patient endoscopy instructors who are willing to spend the extra time needed to foster their own technical skills development. The results of the present study indicate that the magnitude of such training effects on times for the common procedure of outpatient colonoscopy is substantial. Accordingly, any assessment of endoscopy instructor performance must take these procedure time effects into consideration. Engaged endoscopy instructors cannot achieve benchmarks for case throughput or billings that are applicable to their clinical peers who operate alone. The greater the teaching involvement, the greater was the impact on 'performance standards'. Academic and health care institutional administrators must be aware of such differential capabilities in the deployment of personnel and resources. It is also necessary to consider these effects when resident training is distributed into community facilities where the endoscopist instructors depend solely on fee-for-service income.

Finally, it is worth speculating on the impact of instructional imperatives in other clinical and procedural domains. It is probable that similar effects influence other technical activities such as those in many surgical disciplines and other procedurally oriented medical specialties such as interventional cardiology and radiology. Clearly, quantification of these effects is equally important in the evaluation of performance in a multitude of other disciplines.

\section{REFERENCES}

1. McCashland T, Brand R, Lyden E, et al. The time and financial impact of training fellows in endoscopy. Am J Gastroenterol 2000;95:3129-32.

2. Yong E, Zenkova O, Saibil F, et al. Efficiency of an endoscopy suite in a teaching hospital: Delays, prolonged procedures and hospital waiting times. Gastrointest Endosc 2006;64:760-4.

3. Zamir S, Rex DK. An initial investigation of endoscopy efficiency in endoscopy delivery. Am J Gastroent 2002;97:1968-72.

4. Bridges M, Diamond D. The financial impact of teaching surgical residents in the operating room. Am J Surg 1999;177:28-32.

5. Koperna T. How long do we need teaching in the operating room? The true costs of achieving surgical routine. Langenbecks Arch Surg 2004;389:204-8.

6. Babineau TJ, Becker J, Gibson G, et al. The cost of operative training for surgical residents. Arch Surg 2004;139:366-70.

7. Traverso LW, Koo KP, Hargrave K, et al. Standardizing laparoscopic procedure time and determining the effect of patient age/gender and presence or absence of surgical residents during operation. A prospective trial. Surg Endosc 1997;11:226-9.

8. Woolson ST, Kang MN. A comparison of the results of total hip and knee arthroplasty performed on a teaching service or a private practice service. J Bone Joint Surg 2007;89:601-7.

9. Auerbach JD, Lonner BS, Antonacci MD, et al. Perioperative outcomes and complications related to teaching residents and fellows in scoliosis surgery. Spine 2008;33:1113-8.

10. Farnworth LR, Lemay DE, Wooldridge T, et al. A comparison of arthroscopic times in ACL reconstruction between orthopedic faculty and residents. The financial impact of orthopedic surgical training in the operating room. Iowa Orthoped J 2000;21:31-5. 


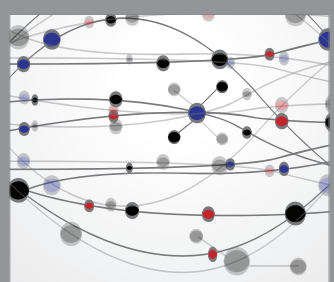

The Scientific World Journal
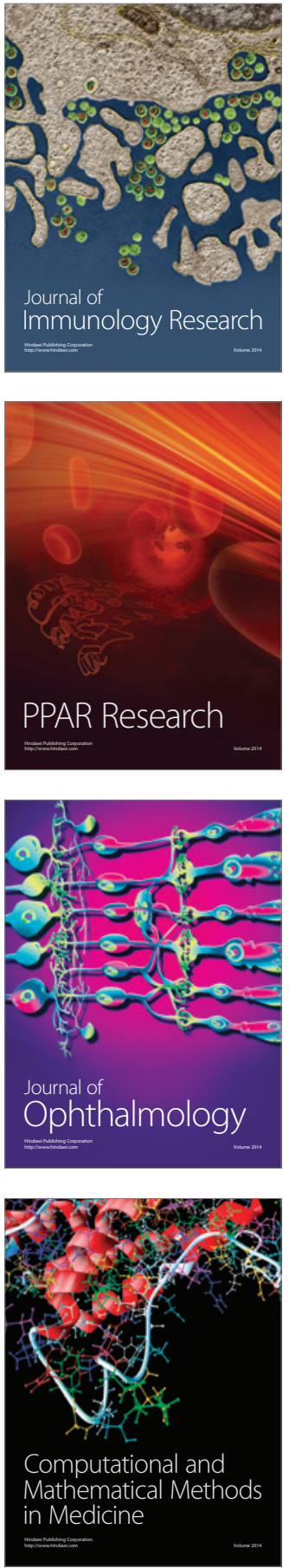

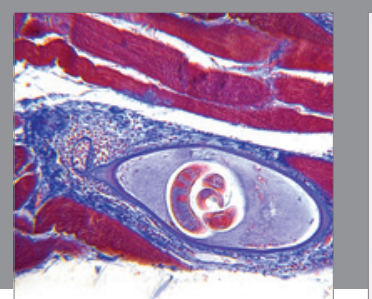

Gastroenterology Research and Practice

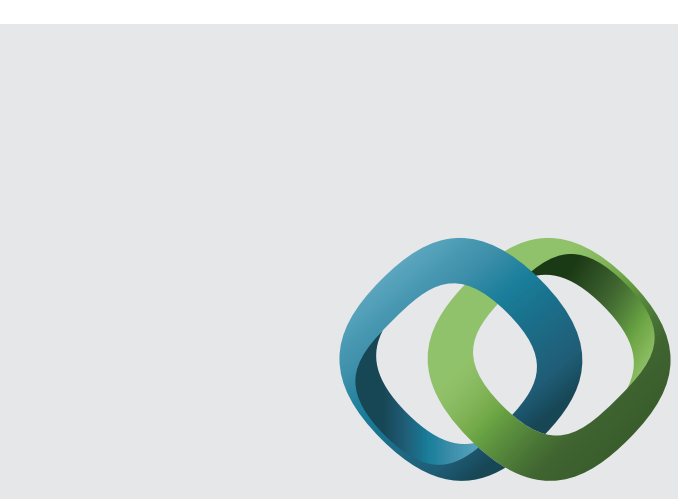

\section{Hindawi}

Submit your manuscripts at

http://www.hindawi.com
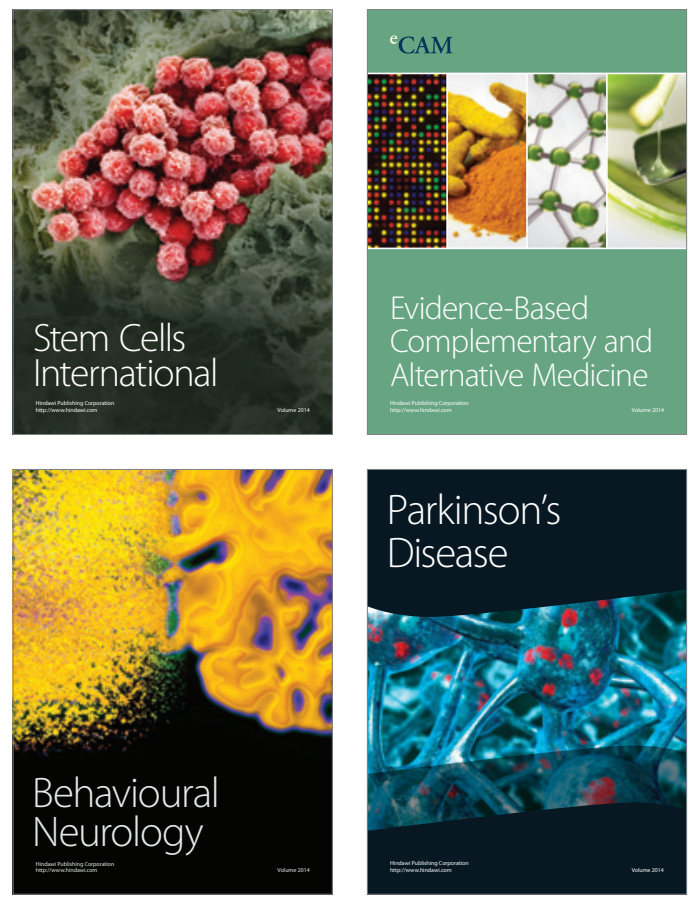
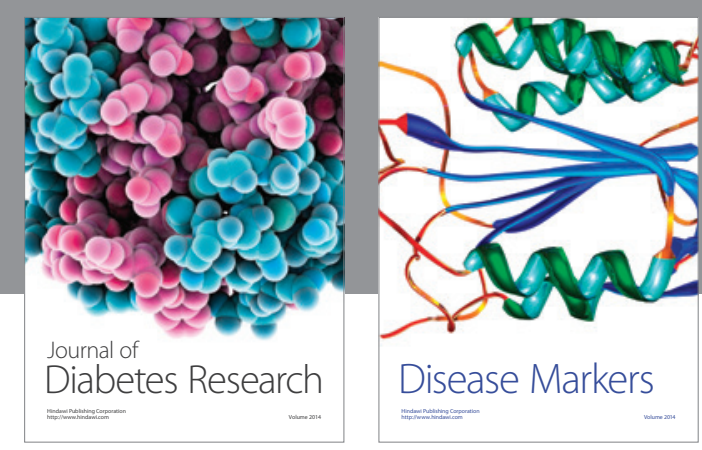

Disease Markers
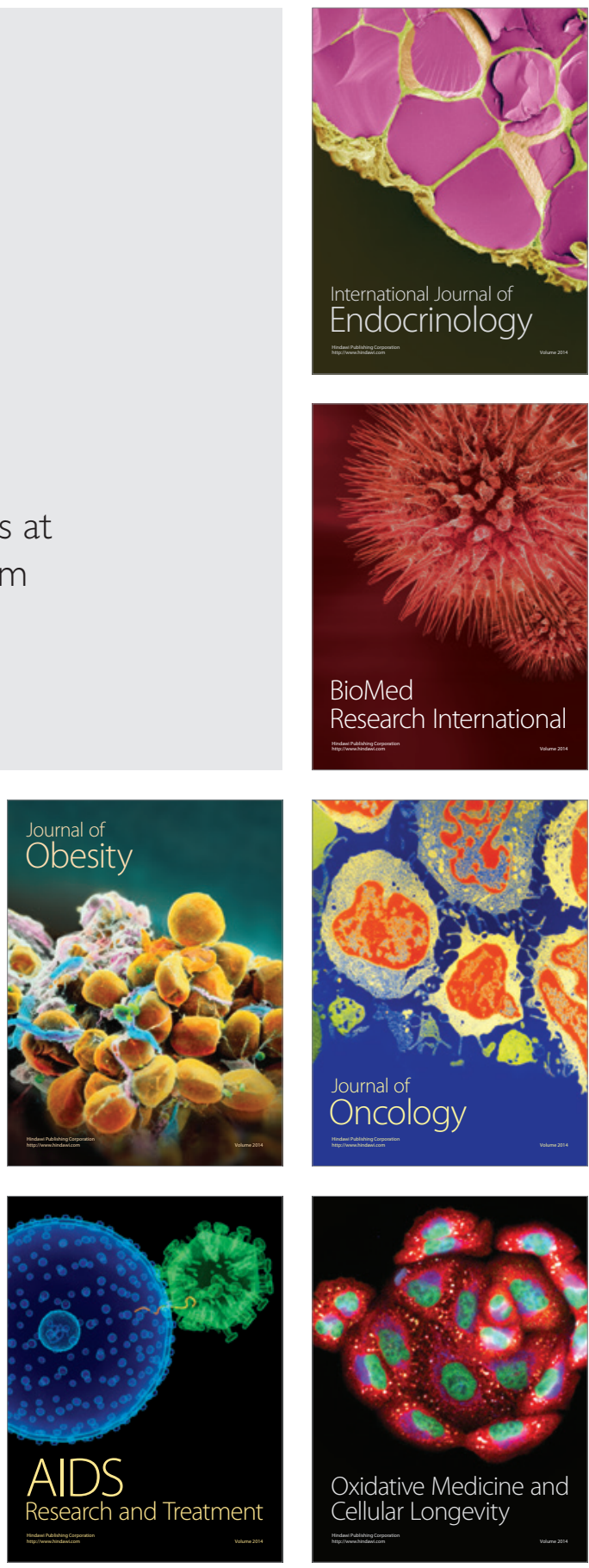